\title{
The Assessment of Knowledge, Behaviors, and Anxiety Levels of the Orthodontists about COVID-19 Pandemic
}

\author{
Hanife Nuray Yilmaz (iD, Elvan Onem Ozbilen (iD
}

Department of Orthodontics, Faculty of Dentistry, Marmara University, Istanbul, Turkey

Cite this article as: Yilmaz HN, Ozbilen EO. The Assessment of Knowledge, Behaviors, and Anxiety Levels of the Orthodontists about COVID-19 Pandemic. Turk J Orthod 2020; 33(4): 224-31.

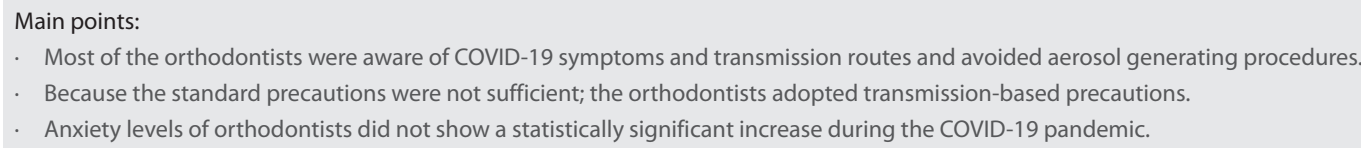

\section{ABSTRACT}

Objective: A new viral disease called Coronavirus disease-19 (COVID-19) affected the whole world because of its characteristics of spreading rapidly via respiratory droplets and aerosol. As one of the most aerosol-generating occupations, dentists are at high risk and are recommended to treat emergency cases only. We aimed to assess the general knowledge, emergencies, personal precautions, and avoided behaviors among the orthodontists and also their anxiety levels, during COVID-19.

Methods: A survey research, including demographic information, general knowledge about COVID-19, treatment strategies, protective measures, and Generalized Anxiety Disorder (GAD) 7 test, was conducted via a web-based questionnaire ( 1 open-ended and 26 closed-ended questions). A total of 215 orthodontists older than 20 years of age and practicing in different regions of Turkey were included in this study. The answers received within the first 10 days were included.

Results: Most of the orthodontists were aware of COVID-19 symptoms and transmission routes ( $n=159$ and $n=183$, respectively). Almost all of them treated only emergency cases $(n=209)$. Orthodontic emergencies were reported mostly as injury due to band/bracket failure, soft/hard tissue trauma, and problems in retention appliances $(n=197, n=186$, and $n=81$, respectively). The participants also avoided aerosol-generating procedures and used transmission-based protective equipment. The prevalence of GAD was 16.7\% during COVID-19, and there was no statistically significant difference when it was stratified by gender, age, city, and COVID-19 related questions ( $p>0.05$ ).

Conclusion: The orthodontists followed the guidelines and took protective measures during COVID-19, and the majority had subthreshold anxiety levels.

Keywords: Anxiety, COVID-19, emergencies, orthodontists, personal protective equipment

\section{INTRODUCTION}

Last December, a new pandemic caused by Severe Acute Respiratory Syndrome Coronavirus-2 (SARS-CoV-2) had started and affected people all around the world (1-3). The World Health Organization named the disease as Coronavirus disease-19 (COVID-19) (4). Most of the patients present symptoms such as fever, dry cough, and shortness of breath or they might be asymptomatic; furthermore, a small percentage of the cases show more severe complications such as acute respiratory distress syndrome or even death (5).

Main transmission routes of SARS-CoV-2 were reported to be contact transmission, droplets transmission, and airborne transmission $(2,6)$. Furthermore, saliva contains the virus due to the pathway which uses to invade the 
cells $(6,7)$. Recent studies suggest that asymptomatic patients, patients in their incubation period, and mildly symptomatic patients can spread the virus $(8,9)$.

Taking into consideration the routes of transmission, it is obvious that dentists, dental staff, and patients are at high risk during dental treatment (6). An article published in the New York Times reported that dentists have a greater risk to be affected by COVID-19 than the general physicians and nurses (10). In dental procedures, an increased number of droplets and aerosol can be generated. Although large droplets usually fall to the ground or surrounding objects, small droplets or aerosol remain in the air and even travel further (11). After landing on surfaces, SARS-CoV-2 can survive on the surfaces from hours to several days and in aerosol for up to 3 hours $(6,12)$. It was suggested to postpone routine dental treatments and provide treatment just for dental emergencies because of the aerosol-generating procedures, close contact with the patient's oropharyngeal region, and the cross-contamination risk because of the infected surfaces/objects in the clinic $(6,13)$. Because even the asymptomatic patients can spread the virus, every patient in the dental clinic should be considered as a potential COVID-19 carrier, and the dentists should avoid aerosol-generating procedures, use personal protective equipment (PPE), and follow disinfection procedures as recommended in the guidelines $(6,14,15)$.

Orthodontic treatment is a continuous, long-term treatment and usually needs to be followed-up every 2-6 weeks. During the COVID-19 pandemic, appointments have been interrupted and thus might affect the psychology of both the patients and the orthodontists. In most countries, dental emergencies have been regulated by the government, but there is a lack of information about orthodontic management. Although most of the orthodontic patients do not show urgent situations, we still need more detailed guidelines and consensus to understand what constitutes a real emergency for orthodontic patients, which will ensure the safety of both the patients and the orthodontists. There are few studies in literature that report orthodontic emergencies, how the orthodontist can manage their patients remotely, whether there is a need for treatment in the clinic, and what the protective measures should be (16-18). In this study, with the help of a survey, we aimed to assess the general knowledge about COVID-19, what is seen as an orthodontic emergency, which protective equipment or methods are preferred, and what the preferred communication methods with the patients are because the studies on this subject are not many. In addition, a test was added at the end of the questionnaire to measure the anxiety level of orthodontists because studies are showing mental health problems and anxiety among healthcare workers after Severe Acute Respiratory Syndrome and Middle East Respiratory Syndrome (19).

\section{METHODS}

The survey research was conducted in Marmara University, Faculty of Dentistry, Department of Orthodontics, and the study was approved by The Republic of Turkey, Ministry of Health, COVID-19 Scientific Research Evaluation Commission (02.05.2020, T11_25_26), and Marmara University, Faculty of Dentistry, the
Ethical Committee of Clinical Research (15.05.2020, 2020/14, Istanbul, Turkey). A web-based questionnaire was prepared by using Google form (Google Inc., Mountain View, CA, USA), which is an online survey tool and sent through e-mail to the registered orthodontist in Turkey. Informed consents were not taken from the participants because it was a web-based questionnaire and the participation was voluntary. The questionnaire comprised four sections. In the first section, demographic information such as age, gender, city, and the working place was collected. The second section comprised general questions about COVID-19, such as questions related to source of the information, whether the orthodontists themselves or people around them have sufficient information about the symptoms and transmission routes of COVID-19, whether adequate precautions have been taken in the orthodontists' working area, and whether the orthodontists consider themselves to be in a high-risk position with regard to the transmission. The third section comprised the orthodontic treatment strategies and the protective measures, which the orthodontists have taken during the COVID-19 outbreak. Orthodontists were asked whether they work during the COVID-19 outbreak; whether they avoid bonding/debonding procedures or using high-speed or low-speed handpieces and 3-way syringe; whether they apply preprocedural mouth rinse; and whether their patients want to continue routine orthodontic treatment. The questionnaire also included questions about the treatment type (all treatments or emergencies), communication methods, orthodontic interventions considered as emergencies, the types of PPE used, and the highest impact of the COVID-19 outbreak on them. In the last section, to measure the orthodontists' anxiety level, the Turkish version of the 7-item Generalized Anxiety Disorder (GAD) test was applied. It was used to evaluate how often the participants were bothered by each related item in the questionnaire during the last 2 weeks. Response options were "not at all," "several days," "more than half the days," and "nearly every day," scored as 0, 1, 2, and 3, respectively. In the GAD-7, the score of 10 or above was used as the cutoff point for the diagnosis of anxiety as was reported in the original article (20).

The data received within the first 10 days after the questions were sent via e-mail were included in this study. A total of 220 orthodontists attended the survey; however, only 215 of them were included in this study. Five people who left unanswered questions were excluded from the study.

\section{Statistical Analysis}

The data were analyzed using The Statistical Package for Social Sciences version 25.0 software (IBM Corp.; Armonk, NY, USA). Descriptive analyses were conducted to describe the demographic characteristics and COVID-19-related answers. The results were shown as frequency and percentage for categorical variables. To analyze the distribution difference between categorical variables, Chi-square test or Fisher exact probability test was performed. Logistic regression analysis was performed to determine which factors affect anxiety together, and the forward conditional method was used. The suitability of the model was evaluated with the Hosmer-Lemeshow test. The odds ratio for risk factors was expressed with $95 \%$ confidence intervals. The significance level was set at $\mathrm{p}<0.05$. 


\section{RESULTS}

\section{Demographic Characteristics}

The participants tended to be mostly female (70.2\%), aged 20-34 years (52.1\%), living in Istanbul (52.5\%), and working mostly in private practice $(57.2 \%)$ (Table 1$)$.

\section{COVID-19 Related Questions}

The sources of information about COVID-19 were reported mostly as websites and social media $(n=182$ and $n=169$, respectively); $51.2 \%$ of the orthodontists changed their working situation to a short-time working model (Table 2). Most of the orthodontists reported having sufficient information about the COVID-19 symptoms and transmission routes ( $n=159$ and $\mathrm{n}=183$, respectively), as illustrated in Figure 1 . In contrast, the number of orthodontists who reported taking adequate precautions against COVID-19 at their working place was equal to those who reported taking only partial precautions $(n=88)$. In addition, 120 orthodontists stated that people around them did not have sufficient information about COVID-19 and did not comply with hygiene rules. Of all the participants, 187 orthodontists thought that they were at a high-risk position with regard to contamination (Figure 1). Restricted social life, decreased income, and negatively affected psychology were among the most marked items in the questionnaire because COVID-19 has an impact on them (Table 2).

\begin{tabular}{|c|c|}
\hline Variables & n (\%) \\
\hline Total & $215(100)$ \\
\hline \multicolumn{2}{|l|}{ Gender } \\
\hline Female & $151(70.2)$ \\
\hline Male & $64(29.8)$ \\
\hline \multicolumn{2}{|l|}{ Age } \\
\hline $20-34$ & $112(52.1)$ \\
\hline $35-44$ & $60(27.9)$ \\
\hline $45-54$ & $25(11.6)$ \\
\hline $55-64$ & $16(7.4)$ \\
\hline$>65$ & $2(1)$ \\
\hline \multicolumn{2}{|l|}{ City } \\
\hline Istanbul & $113(52.5)$ \\
\hline Ankara & $24(11.2)$ \\
\hline Izmir & $10(4.7)$ \\
\hline Other & $68(31.6)$ \\
\hline \multicolumn{2}{|l|}{ Working place } \\
\hline Private Practice & $123(57.2)$ \\
\hline University Hospital & $98(45.6)$ \\
\hline Public Institutions and Organizations & $7(3.3)$ \\
\hline \multicolumn{2}{|l|}{$G A D^{\ddagger}$} \\
\hline No & $179(83.3)$ \\
\hline Yes & $36(16.7)$ \\
\hline $\begin{array}{l}\text { GAD: Generalized Anxiety Disorder } \\
\text { GAD }{ }^{\ddagger} \text { was defined as individuals who scored } \geqq\end{array}$ & \\
\hline
\end{tabular}

\section{Orthodontic Treatment and Precautions}

Almost all the orthodontists reported that they treated only emergency cases from $15^{\text {th }}$ of March to $15^{\text {th }}$ of June which was the end of the survey participation period ( $n=209)$ (Figure 2). Injury due to the band or bracket failure and soft and hard tissue

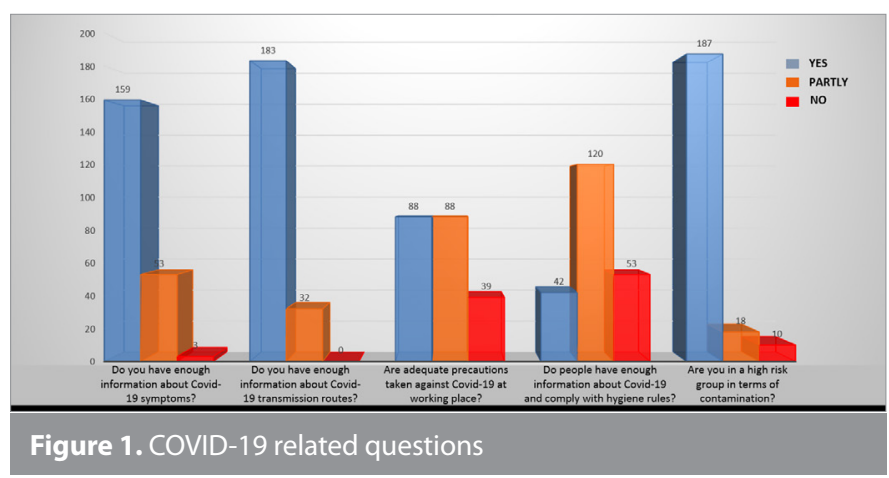

Table 2. Numbers and percentages of the given answers regarding COVID-19 related questions

\section{Variables} n (\%)

Source of information about COVID-19

Websites

$182(84.6)$

Social media

$169(78.6)$

Television

$153(71.2)$

Academic publications

$116(53.9)$

Family and friends

90 (41.8)

Newspaper

30 (13.9)

Radio

$12(5.6)$

Changes in working situation

Short-time working

$110(51.2)$

Vacation

76 (35.3)

Home office

44 (20.5)

Left work

No change

Effects of COVID-19 on lifestyle

Restricted social life

184 (85.6)

Decreased income

$146(67.9)$

Negatively affected psychology

$110(51.2)$

Being far from family

86 (40)

Increased housework

85 (39.5)

Lost health

4 (1.9)

$0(0)$

Use of preprocedural mouth rinse

No need

55 (25.6)

$0.2 \%$ povidone-iodine

50 (23.3)

Chlorhexidine

37 (17.2)

$1 \%$ hydrogen peroxide

32 (14.9)

$2 \%$ povidone-iodine

31 (14.4)

$0.1 \%$ hydrogen peroxide

21 (9.8)

Mouthwash

$16(7.4)$

Salt water

7 (3.3) 


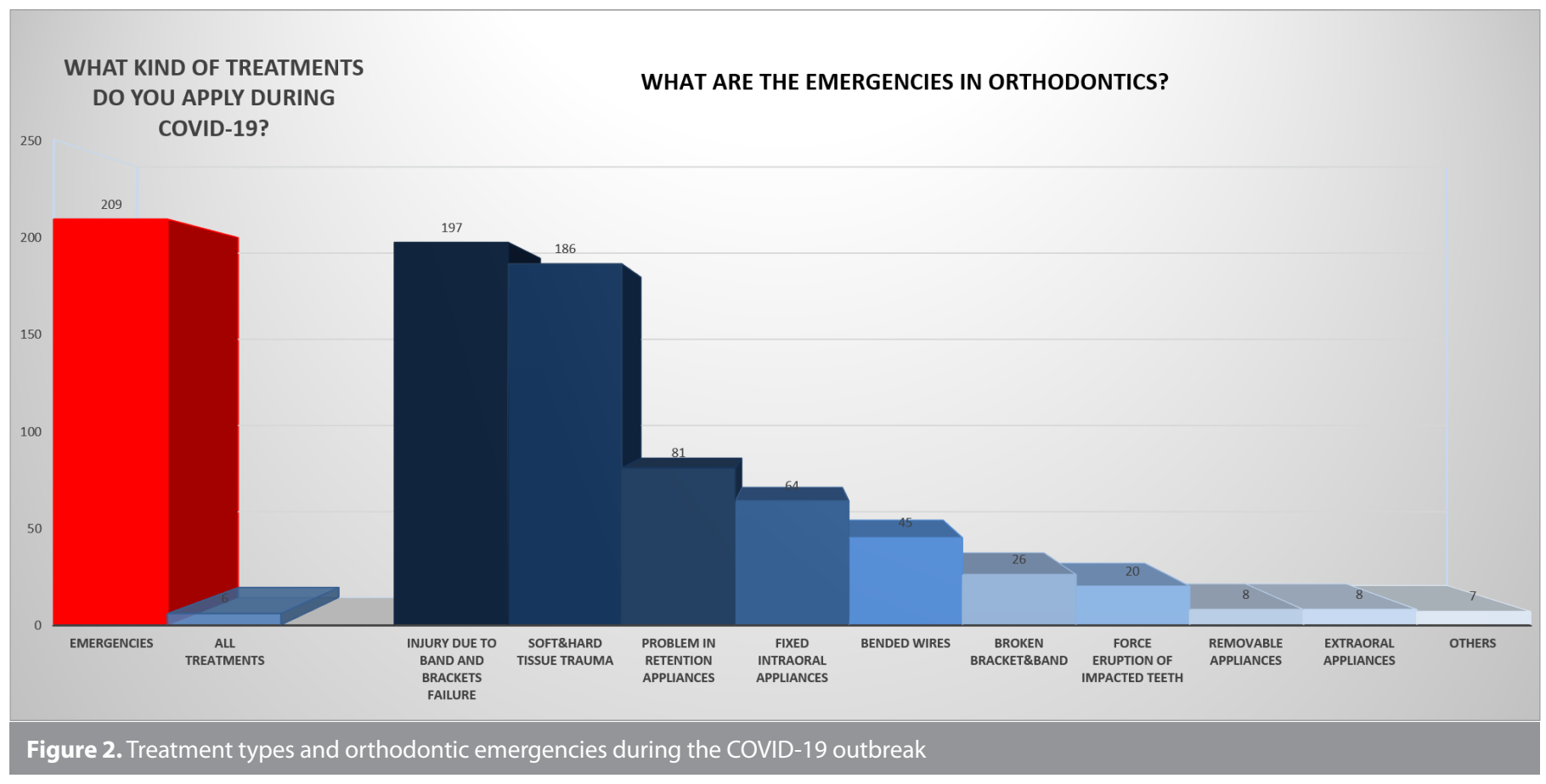

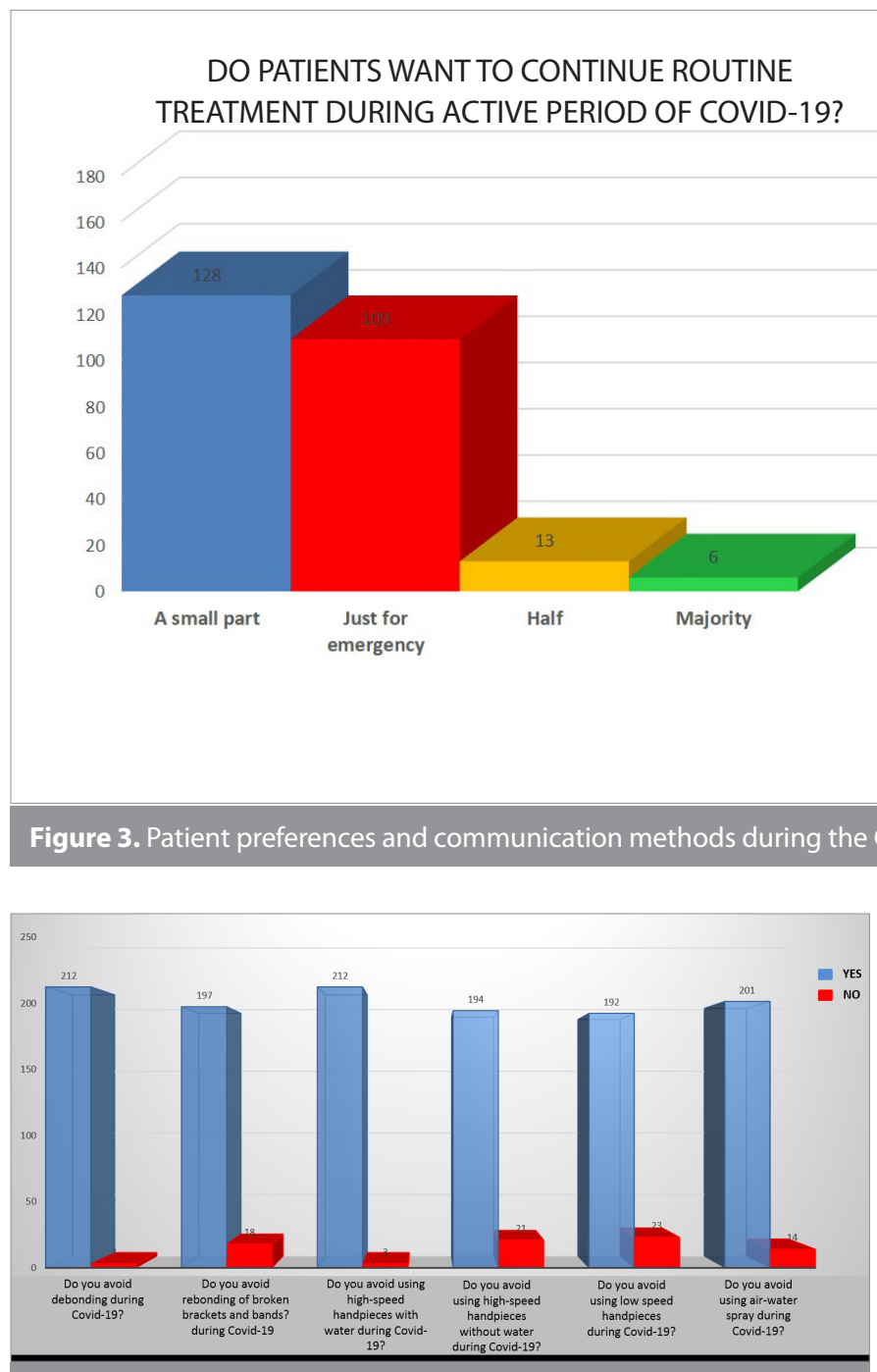

Figure 4. Patient treatment and precautions during the COVID-19 outbreak

\section{COMMUNICATION METHOD WITH THE PATIENTS DURING ACTIVE PERIOD OF COVID-19}

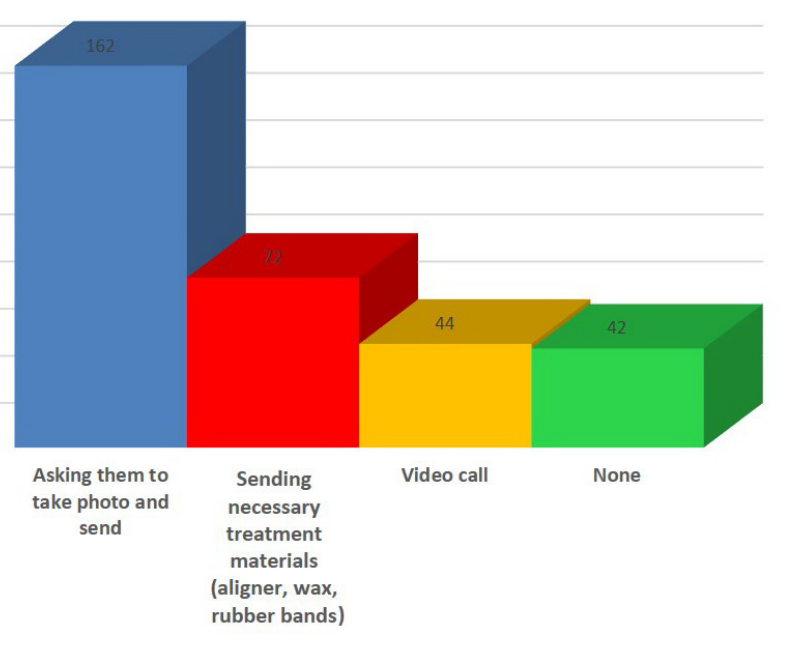




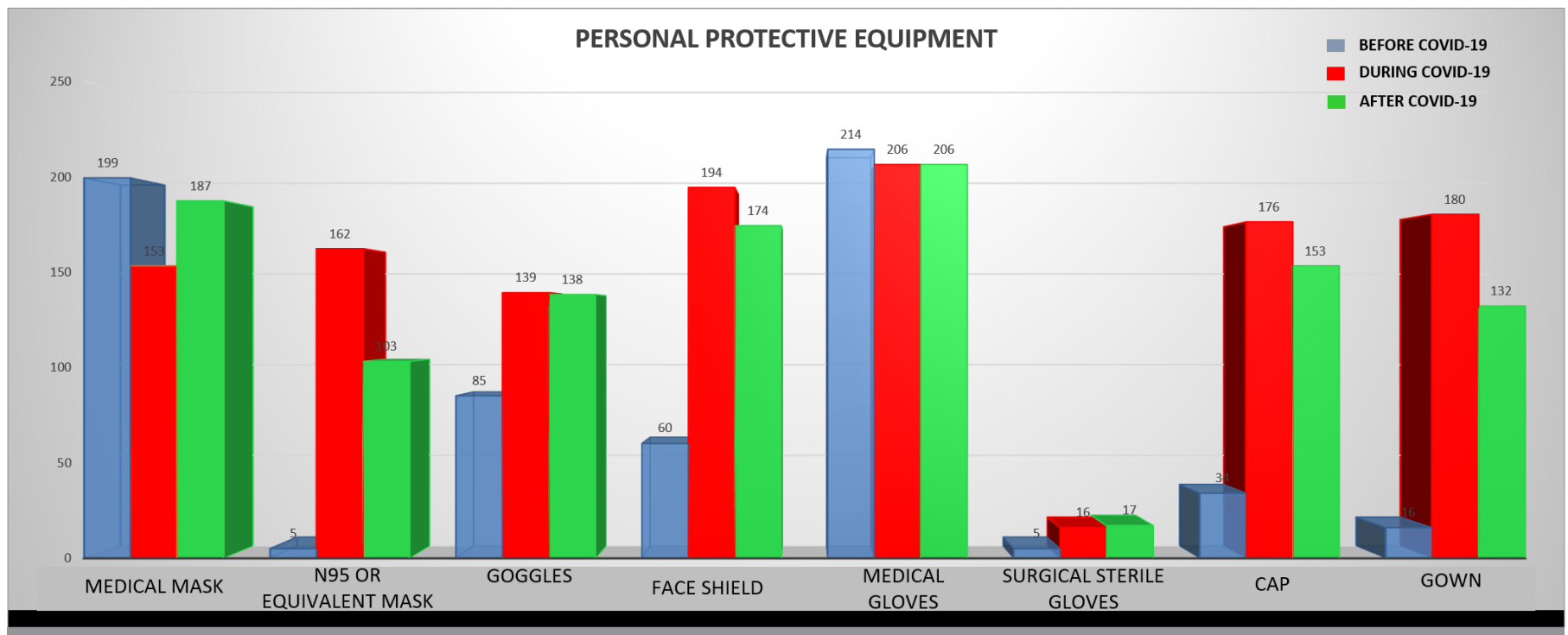

Figure 5. Personal protective equipment preferred before, during, and after the COVID-19 outbreak

Most of the participants avoided the debonding procedure and bonding of broken attachments ( $n=212$ and $n=197$, respectively), using high-speed handpieces with or without water $(n=212$ and $n=194$, respectively), and using low-speed handpieces and 3-way syringe ( $n=192$ and $n=201$, respectively) during the COVID-19 outbreak (Figure 4).

Regarding PPE, medical mask and medical gloves were reported to be used mostly before the COVID-19 outbreak by the orthodontists ( $n=199$ and $n=214$, respectively); however, N95 or equivalent mask ( $n=162)$, goggles $(n=139)$, face shield $(n=194)$, cap $(n=176)$, and gown $(n=180)$ were reported to be used additionally during the COVID-19 outbreak (Figure 5). Furthermore, most of the participants also stated that they would continue to use additional PPE such as N95, face shield, and others after the outbreak as a routine procedure, but the ratio would be lower than the ratio reported during the COVID-19 outbreak. In addition, $23.3 \%$ of the participants reported using $0.2 \%$ povidone-iodine, $17.2 \%$ of them reported using chlorhexidine, and $14.9 \%$ of them reported using $1 \%$ hydrogen peroxide as a preprocedural mouth rinse solution, whereas $25.6 \%$ reported not needing mouth rinse (Table 2).

\section{GAD-7 Test}

The prevalence of GAD was $16.7 \%$ among the orthodontists during the COVID-19 outbreak (Table 1). There was no statistically significant difference when the prevalence of GAD was stratified by gender, age, city, and COVID-19-related questions (Table 3). However, there was a statistically significant difference between the working place and the anxiety levels. The ratio of having anxiety above the threshold (GAD- $7^{3} \geq 10$ points) among the orthodontists working in public institutions and organizations was higher (60\%) (Table 3).

Although there was no statistically significant difference between the answers and anxiety presence distributions, the ratio of having anxiety above the threshold was statistically higher (38.9\%) among those who reported surrounding people as having inadequate knowledge and not complying with hygiene rules (z-test for comparing proportions).

Logistic regression analysis was performed to determine which factors affect anxiety; however, none of them were statistically significant.

\section{DISCUSSION}

This study was one of the first studies that assessed orthodontists' general knowledge about COVID-19, orthodontic emergencies, and behavioral and protective measures taken during the outbreak and was also the first study that measured the anxiety level of orthodontists. Because of the transmission routes of SARS-CoV-2 $(6,15)$ and the knowledge of asymptomatic people and people in their incubation period who can infect others (9), it is obvious that all dentists, including orthodontists, can be exposed to the virus easily $(6,10,13$, 17). Although the orthodontic practice generates less aerosol than some other dental specialties, insertion of bands and brackets, attachments of clear aligners, and removal of residual adhesive create aerosol, and also saliva droplets which contain SARS-CoV-2 might splash while removing or inserting orthodontic wires and ligatures (7). Most of the guidelines do not have adequate information about orthodontic management during the COVID-19 outbreak. Because the orthodontic treatment is a continuous treatment and needs follow-up every 2-6 weeks, it should be clarified what constitutes a real emergency in orthodontics and how to manage it with specific protocols during this outbreak. In this study, together with the general knowledge about COVID-19, we tried to evaluate what constituted orthodontic emergency according to the orthodontists, about the changes in their working situations, and about the personal protective measures used. In this study, mostly websites and social media were reported as 
Table 2. Numbers and percentages of the answers to COVID-19 related questions

\begin{tabular}{|c|c|c|c|}
\hline \multirow[b]{2}{*}{ Variables } & \multicolumn{3}{|c|}{ GAD $^{*}$} \\
\hline & No, n (\%) & Yes, n (\%) & $\mathbf{p}$ \\
\hline \multicolumn{4}{|l|}{ Gender $^{1}$} \\
\hline Female & $122_{\mathrm{a}}(80.8)$ & $29_{a}(19.2)$ & 0.138 \\
\hline Male & $57_{a}(89.1)$ & $7_{a}(10.9)$ & \\
\hline \multicolumn{4}{|l|}{$\mathrm{Age}^{2}$ (years) } \\
\hline $20-34$ & $92_{a}(82.1)$ & $20_{a}(17.9)$ & 0.953 \\
\hline $35-44$ & $51_{a}(85)$ & $9_{a}(15)$ & \\
\hline $45-54$ & $21_{a}(84)$ & $4_{a}(16)$ & \\
\hline $55-64$ & $13_{a}(81.3)$ & $3_{a}(18.8)$ & \\
\hline$>65$ & $2_{a}(100)$ & $0_{a}(0)$ & \\
\hline \multicolumn{4}{|l|}{ City $^{2}$} \\
\hline Istanbul & $99_{\mathrm{a}}(87.6)$ & $14_{\mathrm{a}}(12.4)$ & 0.220 \\
\hline Ankara & $18_{a}(75)$ & $6_{a}(25)$ & \\
\hline Izmir & $9_{a}(90)$ & $1_{a}(10)$ & \\
\hline Other & $53_{a}(77.9)$ & $15_{\mathrm{a}}(22.1)$ & \\
\hline \multicolumn{4}{|l|}{ Working place ${ }^{2}$} \\
\hline Public institutions and organizations & $2_{a}(40)$ & $3_{b}(60)$ & $0.034^{*}$ \\
\hline Private practice & $97_{a}(87.4)$ & $14_{a}(12.6)$ & \\
\hline University hospital & $69_{a}(80.2)$ & $17_{a}(19.8)$ & \\
\hline More than one place & $11_{a}(84.6)$ & $2_{a}(15.4)$ & \\
\hline \multicolumn{4}{|c|}{ Do you have enough information about symptoms of COVID-19? ${ }^{2}$} \\
\hline No & $3_{a}(100)$ & $0_{a}(0)$ & 0.174 \\
\hline Partially & $40_{\mathrm{a}}(75.5)$ & $13_{\mathrm{a}}(24.5)$ & \\
\hline Yes & $136_{a}(85.5)$ & $23_{a}(14.5)$ & \\
\hline
\end{tabular}

Do you have enough information about transmission routes of COVID-19? ${ }^{2}$

$\begin{array}{lrrr}\text { Partially } & 29_{a}(90.6) & 3_{a}(9.4) & 0.308 \\ \text { Yes } & 150_{a}(82) & 33_{a}(18) & \end{array}$

Are adequate precautions taken against COVID-19 at your working place?' No $\quad 32_{a}(82.1) \quad 7_{a}(17.9) \quad 0.956$

Partially $74_{\mathrm{a}}(84.1) \quad 14_{\mathrm{a}}(15.9)$

Yes $\quad 73_{a}(83) \quad 15_{a}(17)$

Do people have enough information about COVID-19 and comply with hygiene rules?'

$\begin{array}{lccc}\text { No } & 39^{\mathrm{a}}(73.6) & 14^{\mathrm{b}}(26.4) & 0.094 \\ \text { Partially } & 104^{\mathrm{a}}(86.7) & 16^{\mathrm{a}}(13.3) & \\ \text { Yes } & 36^{\mathrm{a}}(85.7) & 6^{\mathrm{a}}(14.3)\end{array}$

Are you in a high-risk group in terms of contamination?"

$\begin{array}{lcc}\text { No } & 7_{\mathrm{a}}(70) & 3_{\mathrm{a}}(30) \\ \text { Partially } & 17_{\mathrm{a}}(94.4) & 1_{\mathrm{a}}(5.6) \\ \text { Yes } & 155_{\mathrm{a}}(82.9) & 32_{\mathrm{a}}(17.1)\end{array}$

GAD: Generalized Anxiety Disorder; COVID-19: Coronavirus disease-19 ${ }^{1}$ Chi-square tests; ${ }^{2}$ Fisher exact test. Each subscript letter denotes a subset of GAD categories whose column proportions do not differ significantly from each other at the 0.05 level.

$\mathrm{GAD}^{\ddagger}$ was defined as individuals who scored $\geq 10$ points

the source of information about COVID-19, which coincided with the results of Lim et al. 's study (21). The participants in our study stated that as healthcare workers they had sufficient information about COVID-19 symptoms and transmission routes, which was also in accordance with the literature $(21,22)$. Most of the participants were considered to be in a high-risk group because it was reported in the literature that healthcare workers were at substantial risk owing to pernicious characteristics of COVID-19 $(10,23)$. In addition, the number of orthodontists who notified that adequate precautions were taken against COVID-19 at their working place was equal to those who reported that only partial precautions were taken. This statement might be related to feeling insecure about working at a high-risk position, the shortage of protective equipment, or not trusting the application of protective measures by the employees. The participants did not trust people around them about their COVID-19 related knowledge and hygiene rules. However, in one of the studies, authors reported that respondents carried out precautionary behaviors owing to the outbreak (78.6\% in Wuhan and $63.9 \%$ in Shanghai); the duration and frequency of handwashing and wearing a mask when going out increased significantly. They added that no evidence was found about the associations between sex, age, education, working status, and behavioral responses during the COVID-19 outbreak (24). In contrast, Lim et al. (21) stated according to their respondents' mask-wearing intentions that better messaging was necessary for infection prevention within the household.

In the guidelines and the scientific papers, it was recommended to reschedule patient appointments and treat emergency cases only during the COVID-19 outbreak $(6,13,15)$. In this study, most of the orthodontists reported treating only emergency cases as was suggested. However, they also reported that a small part of their patients wanted to continue routine orthodontic treatment even if it was not recommended. This might be related to insufficient information given to the patients about the progress of their treatments during the COVID-19 outbreak, which might have worried them that the quality of the treatment would deteriorate. This might also be related to the fact that the patients did not understand the severity of the outbreak.

In the literature, the functional or extraoral appliances, problems in the aligners and the retainers, loose brackets and bands, pocking wires, abscess around the molar band, irritation of lip and cheek, and loose elastic chain were reported as orthodontic emergencies $(16,17)$. Although broken brackets and bands, fixed intraoral appliances used for expansion or functional treatment, bent wires, forced eruption, and removable or extraoral appliances were also reported as emergencies in our study; injury due to the band or bracket failure, soft and hard tissue trau$\mathrm{ma}$, and the problems in retention appliances were considered as emergencies with a higher ratio. In an emergency, first, it was suggested to try to manage the situation remotely $(16,17)$. In some cases, even patients or parents can solve the problems at home with guidance. For this purpose, orthodontists can send informative photographs and videos that are either prepared by themselves or available on websites (17). In this study, virtual communication methods such as asking patients to send their photographs or making video calls were most preferred. Furthermore, the participants also provided necessary treatment materials such as aligners, rubber bands, wax, and others, in order not to disrupt the treatment. 
When there is a real emergency and the patient should be seen in the clinic, strict protective measures have to be taken. Aerosol- or droplet-generating procedures should be minimized or avoided if possible $(6,15)$. In this study, the participants mostly avoided debonding procedure, bonding of broken attachments, and using high-speed and low-speed handpieces and a 3-way syringe in order not to generate aerosol, as was recommended in the guidelines. Besides deferring routine dental treatments and avoiding aerosol-generating procedures, it is also important to use proper PPE and decrease the cross-contamination risk while treating emergency cases. For instance, preprocedural mouth rinse was recommended in the literature because SARSCoV-2 was also reported in the saliva (7). The studies showed that mouth rinse with $0.2 \%$ povidone-iodine and $1 \%$ hydrogen peroxide decreased the viral load because of oxidation; however, chlorhexidine did not affect the virus $(6,13)$. In this study, $25.6 \%$ of the participants reported not needing mouth rinse, and $17.2 \%$ of them reported the use of chlorhexidine, which did not coincide with the guidelines and literature findings. Those findings may imply that the participants who stated that they did not need mouth rinse or who used chlorhexidine did not have sufficient information regarding the mouth rinse. However, $23.3 \%$ of them were reported using $0.2 \%$ povidone-iodine, and $14.9 \%$ of them preferred $1 \%$ hydrogen peroxide as was suggested.

Particulate respirators ( $\mathrm{N}-95$ masks or equivalent masks such as FFP2-standard masks or superior) are recommended because the standard medical mask is not effective against SARS-CoV-2loaded aerosol $(14,15)$. Disposable gowns and caps, goggles, or face shields are also suggested together with standard precautions during the outbreak $(14,15)$. In this study, medical mask and gloves were mostly reported to be used before the COVID-19 outbreak. However, during the outbreak, N95 or equivalent mask, goggles, face shield, disposable gowns, and caps together with the standard protective equipment were used by the participants. Furthermore, they claimed that they would continue to use the additional PPE even after the outbreak. It is evident that the standard protective equipment will go out of the ordinary and require more equipment. Hence, how this extra cost can be dealt with by the clinicians or whether this will be reflected in the treatment fees is a question for now.

Regarding the effects of the COVID-19 outbreak, the participants mostly marked the items of restricted social life, decreased income, and negatively affected psychology. It was previously reported in the literature that being isolated and working at highrisk positions might adversely affect the psychology of healthcare workers (19). Healthcare workers suffering from mental health disturbances has also been advocated in some of the previous studies about COVID-19 $(22,23)$. In the last part of this questionnaire, to assess the anxiety level during the outbreak, the Turkish version of the GAD-7 test, which has high validity and reliability similar to the original form, was used (25). The prevalence of GAD was $16.7 \%$, and there was no statistically significant difference when stratified by gender, age, city, and COVID-19-related questions. Qian et al. (24) reported that $32.7 \%$ of Wuhan and $20.4 \%$ of Shanghai participants reported moderate or severe anxiety, which was higher than the results in this study. Huang and Zhao
(22) observed higher percentages (37.4\%) in the healthcare workers; however, there was no statistically significant difference when compared with other occupations. Other studies evaluating the mental health disturbances with the help of different scales reported that mostly subthreshold and mild disturbances were seen in the population $(23,26)$. In the literature, there are conflicting results about associations between GAD and age and gender. Although some of the literature findings reported that females are more vulnerable to stress, the other studies reported no difference between the genders as in the results of this study (22, $24,26,27)$. With regard to the age, Qui et al. (26) reported young adults (18-30 years) as having high-stress levels, and Huang and Zhao (22) observed that people younger than 35 years showed more anxiety symptoms, whereas Qian et al. (24) reported no difference between the age groups in accordance with our study. The only statistically significant difference was between the working place and anxiety presence distributions in this study. The orthodontists working in public institutions and organizations reported higher anxiety levels; however, the number of those was low $(n=5)$, which may not reflect the general results. In addition, the anxiety level was found to be higher among those who reported the surrounding people as having inadequate knowledge about COVID-19 and not complying with hygiene rules. This might imply that the level of anxiety may increase when people feel insecure about protecting themselves and cannot control the people around them; however, the number of the participants was also low in this group.

Because of the restrictions during COVID-19, a web-based questionnaire was used in this study and thus made the participants voluntary. Although it was sent to all registered orthodontists in the country, it should be considered that there is a possibility of selection bias. Furthermore, because the number of participants was relatively small, surveys with larger sample sizes and longterm follow-up for the anxiety might create more generalized results.

As the information about the virus is updated every day, we recommend the orthodontists to update their knowledge. Because people mostly prefer digital platforms such as websites and social media to obtain information, updating the information about the virus on these platforms will provide up-to-date information that will reach more people.

\section{CONCLUSION}

- Most of the orthodontists are aware of COVID-19 symptoms and transmission routes.

- They treat only emergency cases and take recommended transmission-based precautions according to the current guidelines and research.

- By most of the orthodontists, injury due to band bracket failure, soft and hard tissue trauma, and problems in retention appliances were seen as real emergencies.

- $\quad$ During COVID-19, 16.7\% of the participants had been diagnosed with GAD; however, there was no statistically significant difference when the prevalence of GAD was stratified by gender, age, city, and COVID-19-related questions. 
Ethics Committee Approval: This study was approved by Ethics committee of Marmara University, Istanbul, Turkey (Approval No: 15.05.2020, 2020/14).

Informed Consent: Informed consent is not necessary due to the nature of this study.

Peer-review: Externally peer-reviewed.

Author Contributions: Supervision - H.N.Y.; Design - H.N.Y.; , E.O.O.; Resources - H.N.Y., E.O.O.; Materials - H.N.Y., E.O.O.; Data Collection and/ or Processing - H.N.Y., E.O.O.; Analysis and/or Interpretation - H.N.Y.; , E.O.O.; Literature Search - E.O.O.; Writing Manuscript - H.N.Y., E.O.O.; Critical Review - H.N.Y., E.O.O.

Conflict of Interest: The authors have no conflict of interest to declare.

Financial Disclosure: The authors declared that this study has received no financial support.

\section{REFERENCES}

1. Gorbalenya AE, Baker SC, Baric RS, de Groot RJ, Drosten C, Gulyaeva $A A$, et al. Severe acute respiratory syndrome-related coronavirus: The species and its viruses - a statement of the Coronavirus Study Group. Nature Microbiology 2020; 5: 536-44. [Crossref]

2. Li Q, Guan X, Wu P, Wang X, Zhou L, Tong Y, et al. Early Transmission Dynamics in Wuhan, China, of Novel Coronavirus-Infected Pneumonia. N Engl J Med 2020; 382: 1199-207. [Crossref]

3. World Health Organization. Coronavirus disease 2019 (COVID-19) Situation Reports - 52. Accessed 12 March, 2020. Available from: https://www.who.int/docs/default-source/coronaviruse/situation-reports/20200312-sitrep-52-covid-19.pdf?sfvrsn=e2bfc9c0_4.

4. World Health Organization. Novel Coronavirus (2019-nCoV) Situation Reports - 22. Accessed 11 Februry, 2020. Available from: https://www.who.int/docs/default-source/coronaviruse/situation-reports/20200211-sitrep-22-ncov.pdf?sfvrsn=fb6d49b1_2.

5. Huang C, Wang Y, Li X, Ren L, Zhao J, Hu Y, et al. Clinical features of patients infected with 2019 novel coronavirus in Wuhan, China. Lancet 2020; 395: 497-506. [Crossref]

6. Peng X, Xu X, Li Y, Cheng L, Zhou X, Ren B. Transmission routes of 2019-nCoV and controls in dental practice. Int J Oral Sci 2020; 12: 1-5. [Crossref]

7. Sabino-Silva R, Jardim ACG, Siqueira WL. Coronavirus COVID-19 impacts to dentistry and potential salivary diagnosis. Clin Oral Investig 2020; 24: 1619-21. [Crossref]

8. Pan X, Chen D, Xia Y, Wu X, Li T, Ou X, et al. Asymptomatic cases in a family cluster with SARS-CoV-2 infection. Lancet Infect Dis 2020; 20: 410-1. [Crossref]

9. Rothe C, Schunk M, Sothmann P, Bretzel G, Froeschl G, Wallrauch C, et al. Transmission of 2019-nCoV Infection from an Asymptomatic Contact in Germany. N Engl J Med 2020; 382: 970-1. [Crossref]

10. Gamio L. The New York Times, The Workers Who Face the Greatest Coronavirus Risk. Accessed 15 March, 2020. Available from: https:// www.nytimes.com/interactive/2020/03/15/business/economy/ coronavirus-worker-risk.html?searchResultPosition $=8$.

11. Ge ZY, Yang LM, Xia JJ, Fu XH, Zhang YZ. Possible aerosol transmission of COVID-19 and special precautions in dentistry. J Zhejiang Univ Sci B 2020; 21: 361-8. [Crossref]

12. van Doremalen N, Bushmaker T, Morris DH, Holbrook MG, Gamble A, Williamson BN, et al. Aerosol and Surface Stability of SARS-CoV-2 as Compared with SARS-CoV-1. N Engl J Med 2020; 382: 1564-7. [Crossref]

13. Careddu R, Ciaschetti M, Creavin G, Molina F, Plotino G. COVID-19 and dental practice: overview and protocols during pandemic. Giornale Italiano di Endodonzia 2020; 34: 13-9.

14. Centers for Disease Control and Prevention. Coronavirus Disease 2019 (COVID-19), Infection control. Accessed 26 May, 2020. Available from: https://www.cdc.gov/coronavirus/2019-ncov/hcp/infection-control.html.

15. Meng L, Hua F, Bian Z. Coronavirus Disease 2019 (COVID-19): Emerging and Future Challenges for Dental and Oral Medicine. J Dent Res 2020; 99: 481-7. [Crossref]

16. Caprioglio A, Pizzetti GB, Zecca PA, Fastuca R, Maino G, Nanda R. Management of orthodontic emergencies during 2019-NCOV. Prog Orthod 2020; 21: 10. [Crossref]

17. Suri S, Vandersluis YR, Kochhar AS, Bhasin R, Abdallah MN. Clinical orthodontic management during the COVID-19 pandemic. Angle Orthod. 2020. doi: 10.2319/033120-236.1. [Epub ahead of print]. [Crossref]

18. Wang J, Wu Y, Xiong $X$, Fang $X$, Sun W, Yi Y, et al. Differences of psychological status of TMD patients, orthodontic patients and the general population during the COVID-19 epidemic: a cross-sectional study. Research Square. 2020. doi: 10.21203/rs.3.rs-18915/v1. [Epub ahead of print]. [Crossref]

19. Lee SM, Kang WS, Cho AR, Kim T, Park JK. Psychological impact of the 2015 MERS outbreak on hospital workers and quarantined hemodialysis patients. Compr Psychiatry 2018; 87: 123-7. [Crossref]

20. Spitzer RL, Kroenke K, Williams JB, Lowe B. A brief measure for assessing generalized anxiety disorder: the GAD-7. Arch Intern Med 2006; 166: 1092-7. [Crossref]

21. Lim JM, Tun ZM, Kumar V, Quaye SED, Offeddu V, Cook AR, et al. Population anxiety and positive behaviour change during the COVID-19 epidemic: Cross-sectional surveys in Singapore, China and Italy. medRxiv 2020. DOI: http://dx.doi.org/10.2139/ssrn.3576940. [Epub ahead of print]. [Crossref]

22. Huang Y, Zhao N. Generalized anxiety disorder, depressive symptoms and sleep quality during COVID-19 outbreak in China: a webbased cross-sectional survey. Psychiatry Res 2020; 288: 112954. [Crossref]

23. Kang L, Ma S, Chen M, Yang J, Wang Y, Li R, et al. Impact on mental health and perceptions of psychological care among medical and nursing staff in Wuhan during the 2019 novel coronavirus disease outbreak: A cross-sectional study. Brain Behav Immun 2020. doi: 10.1016/j.bbi.2020.03.028. [Epub ahead of print]. [Crossref]

24. Qian M, Wu Q, Wu P, Hou Z, Liang Y, Cowling BJ, et al. Psychological responses, behavioral changes and public perceptions during the early phase of the COVID-19 outbreak in China: A population based cross-sectional survey. medRxiv 2020. doi: https://doi.org/10.1101/ 2020.02.18.20024448. [Epub ahead of print]. [Crossref]

25. Konkan R, Şenormancı Ö, Güçlü O, Aydin E, Sungur MZ. Yaygın Anksiyete Bozukluğu-7 (YAB-7) Testi Türkçe Uyarlaması, Geçerlik ve Güvenirliği. Noro Psikiyatr Ars 2013; 50: 53-8. [Crossref]

26. Qiu J, Shen B, Zhao M, Wang Z, Xie B, Xu Y. A nationwide survey of psychological distress among Chinese people in the COVID-19 epidemic: Implications and policy recommendations. Gen Psychiatr 2020; 33: e100213. [Crossref]

27. Sareen J, Erickson J, Medved MI, Asmundson GJ, Enns MW, Stein M, et al. Risk factors for post-injury mental health problems. Depress Anxiety 2013; 30: 321-7. [Crossref] 